\title{
Surgical Management and Outcome of Adnexal Masses during Pregnancy: A 2 Year Retrospective Study
}

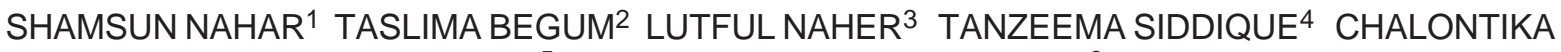 \\ RANI $^{5}$ MOHAMMAD RAIHAN-UL-KABIR ${ }^{6}$
}

\begin{abstract}
:
Objective: To demonstrate adnexal masses during pregnancy

Materials and Methods: This retrospective hospital based study was carried out in the department of Obstetrics \& Gynaecology of Sir Salimullah medical college \& Mitford hospital, Dhaka, between June 2007 to June 2009.

Results: Among 5320 live births fourteen pregnancies with adnexal masses were detected during the study period. The mean age group of the patients was 26.6 year (range 18-42 yrs), the mean gestational age at which adnexal masses were detected was 17 weeks (range 5-36 wks) and the mean gestational age at the time of surgery was 24 weeks (range 6-41wks).

Conclusion: This study demonstrated a high rate of surgical intervention of adnexal masses during pregnancy. Most cases were benign in character and malignancy rate was very low.
\end{abstract}

\section{Introduction:}

Management of adnexal mass in a pregnant woman presents a challenge as there is concern regarding maternal as well as foetal outcome. Currently adnexal masses have been noted to occur upto $1 \%$ of all gestation ${ }^{1}$. Most pregnant women visit obstetrician from the very early weeks of gestation. With the widespread use of routine abdominal ultrasound examination during pregnancy, adnexal masses are observed with increasing frequency and are detected in $1-2 \%$ of pregnancies $2,3,4$. The common adnexal masses diagnosed during pregnancy are - functional cysts, benign neoplasm or malignant ovarian tumours. ${ }^{5}$ More than $90 \%$ are unilateral, non complex and less than $5 \mathrm{~cm}$ in diameter and are functional cysts ${ }^{6}$. Functional cysts are clear cysts of $<5 \mathrm{~cm}$ size and asymptomatic at presentation but have been documented as large as $10 \mathrm{~cm}$ in size. ${ }^{5}$ Most of these functional cysts detected during early pregnancy disappear during the first 16 weeks of pregnancy and present no risk to the pregnancy 6,7 . The persistent masses are pathological, majority being of benign nature of which cystadenoma and benign cystic teratoma are common ${ }^{5}$. Seven percent of diagnosed adenexal masses during pregnancy are malignant ${ }^{4}$ with reported incidence of $1 / 8000$ to $1 / 20,000$ deliveries ${ }^{8}$. Careful evaluation of adnexal masses during pregnancy is required to determine the nature of the mass. ${ }^{9,4}$

Ultrasonography and coloured doppler with tumour markers help to differentiate benign from malignant. Interpretation of tumour markers is done with caution in pregnant patients ${ }^{5}$. The CA 125 levels have been reported elevated in pregnancy especially in the first trimester \& during delivery ${ }^{10}$. Elevated levels of $\alpha$ feto protein (AFP) have been observed in pregnancies carrying fetus with neural tube defects though LDH levels have not been affected by pregnancies. ${ }^{5}$ The incidence of adnexal masses requiring surgical management in pregnancy has been reported to be 1 to $2.3 \%$ of all gestation. ${ }^{11}$ The need for surgical intervention is considered in the following conditions when malignancy is suspected, an acute complication develops because of torsion, rupture or haemorrhage, the sheer size of the tumour is likely to cause rupture or obstructed labour ${ }^{5}$. Surgery of adnexal mass during pregnancy

1. Associate Professor of Obstetrics \& Gynaecology, SSMC \& Mitford Hospital.

2. Assistant Professor(OB/GYN), SSMC \& Mitford Hospital

3. Registrar (OB/GYN), SSMC \& Mitford Hospital

4. IMO (OB/GYN), SSMC \& Mitford Hospital

5. Assistant Registrar (OB/GYN), SSMC \& Mitford Hospital

6. Internee Doctor, SSMC \& Mitford Hospital 
increases the risk of abortion and preterm deliveries and intrauterine growth retardation (IUGR). ${ }^{5}$ Traditionally surgical management can be done during the second trimester. Some recent data suggest that adnexal surgery during the late second or early third trimester poses the greatest risk of preterm delivery or IUGR or both.$^{12}$ The time window of early to mid second trimester of pregnancy has been associated with a lower risk of pregnancy complications with elective surgery for an adnexal mass ${ }^{5}$. It was recommended to avoid complication such as torsion, rupture and risk of delayed diagnosis of malignancies ${ }^{13}$.

\section{Methods:}

This retrospective study was carried out at the department of Obstetrics \& Gynaecology, Sir Salimullah Medical College and Mitford Hospital, Dhaka, from June 2007 to June 2009. All pregnant women diagnosed with adnexal masses were enrolled into the study. The data was collected on maternal age, parity, gestational age at diagnosis, at surgery and at delivery. Ultrasonographic features, complications observed due to surgery and histopathological diagnosis of adnexal masses were noted.

\section{Results:}

Among 5320 live births delivered in this hospital during the study period, total number of cases were 14 . Pregnancies with adnexal masses was found to be 1 in 380 live births.

Mean maternal age was 26.6 years (range $18-42$ yrs) and mean parity was 2.2 (range $0-5$ ) at the time of diagnosis. Mean gestational age at which adnexal masses were detected was 17 weeks (range 5-36 wks), mean gestational age at the time of surgery was 24 weeks (range 6-41wks), mean gestational age at the time of delivery $36 \mathrm{wks}$ (range 28-41wks). The size of adnexal masses varied between $(5-30 \mathrm{~cm})$. Most of the cases were unilateral, only one (7.2\%) case was found bilateral.

Of the total 14 cases with adnexal masses, 4(28.4\%) cases were diagnosed during the $1^{\text {st }}$ trimester, $8(57.2 \%)$ cases during the $2^{\text {nd }}$ trimester and $2(14.2 \%)$ cases during the third trimester. All patients with adnexal masses were surgically managed. Nine (64.2\%) patients suffered from abdominal pain which was the most common presenting symptoms and was diagnosed as torsion, other patients were diagnosed

Table-I

Distribution of time of laparotomy with complications ( $n-14)$ :

\begin{tabular}{lclc}
\hline Trimester & Laparotomy & $\begin{array}{l}\text { Types of } \\
\text { Complication }\end{array}$ & $\begin{array}{c}\text { Frequency of } \\
\text { complication (\%) }\end{array}$ \\
\hline $1^{\text {st }}$ & $3(27.7 \%)$ & 1 abortion & $7.2 \%$ \\
$2^{\text {nd }}$ & $9(64.2 \%)$ & $12^{\text {nd }}$ trimester miscarriage & $14.4 \%$ \\
& & 1 threatened abortion in & \\
& & late $2^{\text {nd }}$ trimester & \\
$3^{\text {rd }}$ & $1(7.2 \%)$ & No complication & $0 \%$ \\
Post partum & $1(7.2 \%)$ & No complication & $0 \%$ \\
\hline
\end{tabular}

Table-II

Pathological findings of adnexal masses:

\begin{tabular}{lcc}
\hline Name of tumour & Frequency & Percentage \\
\hline Benign cystic teratoma & 3 & $21.6 \%$ \\
Serous cystadenoma & 4 & $28.4 \%$ \\
Functional ovarian cyst & 2 & $14.2 \%$ \\
Endrometrioma & 2 & $14.2 \%$ \\
Mucinous cyst adenoma & 1 & $7.2 \%$ \\
Parovarian cyst & 1 & $7.2 \%$ \\
Dysgerminoma (malignant) & 1 & $7.2 \%$ \\
\hline
\end{tabular}


at routine ultrasonographic examination and were free of symptoms. The most common (64.2\%) indication for emergency surgery was torsion.

In this study, 3(27.7\%) patients and 9(64.2\%) patients were operated during the first and second trimester respectively (Table-I).

Pathological findings of the ovarian cyst after operations showed functional ovarian cyst 2(14.2\%), serous cyst adenoma 4(28.4\%), benign cystic teratoma $3(21.6 \%)$, endometrioma 2(14.2\%), mucinous cyst adenoma $1(7.2 \%)$, dysgerminoma $1(7.2 \%)$ \& parovarian cyst $1(7.2 \%)$ (Table-II).

Miscarriage occurred in one patient 1(7.2\%), who had been operated during the first trimester. Among 9 (64.2 $\%)$ patients with features of torsion, all had undergone laparotomy during second trimester, of which two needed tocolytic to prevent threatened abortion. Amongst them one became inevitable abortion and another developed preterm labour later on and needed caesarian section for fetal distress.

\section{Discussion:}

The incidence of adnexal masses developing during pregnancy is $1: 8000-20,000$ live births, according to several series. ${ }^{(14,8)}$ In this study, incidence of adnexal masses in pregnancy was found to be 1:380 live births. This incidence varies from the other studies and appears to be high. This might be due to fact that this is a tertiary care centre and this study is hospital based study, not a population based study.

Sizes of adnexal masses ranged between $5-30 \mathrm{~cm}$, approximately half of all adnexal masses were below $8 \mathrm{~cm}$, a quarter was between $7-10 \mathrm{~cm}$, remaining quarter above $10 \mathrm{~cm}$. Of the masses observed, 93\% were unilateral and $7 \%$ bilateral which correlates with the study by Balci and Gezginc ${ }^{14}$.

Several studies show the malignancy rate as 1:500018000 live births ${ }^{13,15}$. In this study, malignancy rate was 1:5324, which correlates with other study. In a study by Rama it has been shown that ovarian malignancies in association with pregnancy are epithelial ovarian cancer in $35 \%$, germ cell tumours in $33 \%$, dysgerminoma in $30 \%$, gonadal stromal tumours in $20 \%$ cases. $^{5}$

Diagnosis of adnexal masses during pregnancy is an important problem. Nearly all pregnant women visit obstetricians from very early weeks of gestation. As ultrasonographic evaluation is now widely used, the detection rate of adnexal masses have been increased overtime. The use of ultrasonography has resulted in the detection of asymptomatic and clinically unapparent lesion ${ }^{1}$. The rate of detection is highest during the $1^{\text {st }}$ trimester, as shown by Ueda and Ueki who detected $90.3 \%$ of tumour like lesions and $78.8 \%$ of benign tumour before $10^{\text {th }}$ gestational weeks ${ }^{15}$. In this study $1^{\text {st }}$ trimester diagnosis of adnexal cysts is (28.4\%).

The torsion rate of these adnexal masses during pregnancy is 10 to $15 \% .{ }^{16}$ Torsion is mostly seen at 8-16 wks of gestation at which time the uterus grows faster, then at the puerperal period during which uterus involutes and gets smaller rapidly ${ }^{6}$. In this series the torsion rate is $64.2 \%$.

Cancer antigen (CA125) level especially during the $1^{\text {st }}$ trimester, are not useful in the detection of ovarian cancers during pregnancy ${ }^{17}$ and was not done in this study.

It has been reported that the majority of adnexal masses during $1^{\text {st }}$ trimester of pregnancy are corpus luteum or other functional cysts that usually resolve by 16 wks of gestation? The most frequently seen benign ovarian neoplasm during pregnancy is benign cystic teratoma (40\%). The corpus luteum of pregnancy and simple cysts are the other frequently seen masses (29\%). ${ }^{18,19}$ Malignant ovarian tumour hold $2-6 \%$ of adnexal masses detected during pregnancy ${ }^{13,20}$. Epithelial ovarian tumour make up $27.6 \%$ of these malignant tumour, followed by borderline tumours by $20.5 \% 21$. In this series post operative pathological findings of adnexal masses were: benign cystic teratoma 3(21.6\%), serous cyst adenoma 4(28.4\%), functional ovarian cysts 2(14.2\%), endometrioma 2(14.2\%), mucous cyst adenoma $1(7.2 \%)$, dysgerminoma $1(7.2 \%) \&$ parovarian cyst $1(7.2 \%)$.

The management of adnexal masses associated with pregnancy is controversial. The two most common options are operative intervention of the masses or expectant management. Cyst size, gestational age and sonographic appearance are all need to be considered to formulate a treatment plan.

Bernhard et al reported that $76 \%$ of adnexal masses identified by ultrasonography during pregnancy were simple cysts that were lesser than $5 \mathrm{~cm}$ in diameter 
and that did not pose a risk to pregnancy ${ }^{14}$. They suggested surgery only for masses that had predictors for persistence and were complex in nature on ultrasonography and larger than $5 \mathrm{~cm}$ in diameter ${ }^{11}$. Several authors have recommended conservative management of adnexal masses that are $\leq 6 \mathrm{~cm}$ in diameter. ${ }^{18}$ Grimes et al reported in their series that $94 \%$ of cysts less than $6 \mathrm{cms}$, spontaneously resolved with expectant management. ${ }^{14}$ These authors also suggested that the pedicle torsion does not occur as long as the cyst is greater than $6 \mathrm{~cm} .{ }^{14} \mathrm{In}$ another study, the resolution rate of cysts smaller than $6 \mathrm{~cm}$ was reported to be $82 \% .^{22}$

Shenard et al, in their 12 year experience reported 60 pregnant patients with adnexal masses. It was also reported that patients had undergone laparotomy between the $12^{\text {th }}$ and $20^{\text {th }}$ wks of pregnancy and the preterm birth rate was $9 \%$ and miscarriage $4.7 \% .^{23}$ In this study laparotomy was done in all cases, the high rate of surgical intervention secondary to the fact that most of the patient were presented with features of acute abdomen i.e. torsion . This study further demonstrates that if surgery is necessary, it may be managed safely, as there was an acceptable complication rate for surgery in pregnant women.

\section{Conclusion:}

The proportion of adnexal masses found in pregnancies was 1 in 380 live births. Most of the masses excised during pregnancy were found to be benign in character; malignancy rate was comparable to other studies. Mean gestational age at which adnexal masses were detected was 17 weeks; mean gestational age at the time of surgery was 24 weeks. Miscarriage occurred in one patient $(7.2 \%)$ who had been operated in first trimester. In second trimester 9(64.2\%) patients had been operated among them $2(14.4 \%)$ developed threatened abortion, one aborted and the other had preterm labour.

\section{References:}

1. Nelson MJ, Cavalieri R, GragamD, Sanders RC.Cysts in pregnancy discovered by sonography.J Clin Ultrasound 1986;14:509-12.

2. Bernhard LM, Klebba PK, Gray DL, Mutch DG.Predictors of persistence of adnexal masses in pregnancy.Obstet Gynecol 1999; 93: 585-89.

3. Platek DN, Henderson CE, Goldberg GL. The management of a persistent adnexal mass in
pregnancy.Am J Obstet Gynecol 1995; 173: 1236-40.

4. Bromley B, Benacerraf B. Adnexal masses during pregnancy: accuracy of sonographic diagnosis and outcome. J Ultrasound Med 1997; 16: $447-52$.

5. J Rama. Management: Adnexal mass in pregnant women. Indian journal of medical \& paediatric oncology 2009; vol. 30 suppl 1; 3334.

6. Christine $\mathrm{H}$, Holschncider. Surgical disease \& disorders in pegnancy. In: Allan H De Cherney, Lawren Nathan, T Murphy Goodwin, Neri Lauter editors. Current diagnosis \& treatment obstetrics \& Gynaecology, 10th edition. Newyork McGrawHill. 2007: 425-26.

7. Whitecar MP,Turner S,Higby MK.Adnexal masses in pregnancy:A review of 130 cases undergoing surgical management .Am J Obstet Gynecol 1999;181:19-24.

8. Roberts JA. Management of gynaecologic tumours during pregnancy. Clin Perinatol 1983;10:369-82.

9. Sherard GB 3rd, Hodson CA, Williams HJ, et al. Adnexal masses and pregnancy: a 12 year experience. Am J Obstet Gynecol 2003; 189: $358-63$.

10. Kobayashi F, Sagawa N, Nakamura K et al. Mechanism and clinical significance of elevated CA 125 levels in the sera of pregnant women. Am J Obstet Gynecol 1989;160:563-66

11. Bernhard LM,Klebba PK,Grey DL,Mutch DG.Predictors of persistence of adnexal masses in pregnancy.Obstet Gynecol999;93:585-89.

12. Whitecar P, Turner S, Higby K. Adnexal masses in pregnancy: a review of 130 cases undergoing surgical management. Am J Obstet Gynecol. 1999; 181: 19-24.

13. Hess LW, Peaceman A, O'Brien WF, Winkel CA, Cruikshank DP, Morrison JC.Adnexal mass occurring with intrauterine pregnancy;report of fifty-four patients requiring laparotomy for definitive management .Am J Obstet Gynecol 1988; 158 :1029- 34. 
14. Balci o, Gezginc K, Karatayli R. Management and outcomes of adenexal masses during pregnancy : A 6- year experience. J Obstet Gynaecol Res August 2008; 34(4) 524- 28.

15. Ueda M,Ueki M.Ovarian tumours associated with pregnancy.Int J GynaecolObstet 1996;55:59-65.

16. Di Saia PJ,Creasman WT.Cancer in pregnancy.In:Di Saia PJ, Creasman WT (eds). Clinical Gynecologic Oncology, $5^{\text {th }}$ edn.St Louis,MO:Mosby,1997;444- 82.

17. Koboyashi F, Sagawa N, Nakamura K et al. Mechanism and clinical significance of elevated CA levels in the sera of pregnant women. Am J Obstet Gynecol 1989 ; 160:563- 66.

18. Parker LP.Ovarian tumours complicating pregnancy. In:Rock JA, Jones HWIII (eds). Telinde's Operative Gynecology, $9^{\text {th }}$ edn. Philadelphia PA: Lippincott Williams \& Wilkins, 2003; 846- 56.
19. Usui R,Minakami $H$, Kosuge $S$, Iwasaki R ,Ohwada M ,Sato I.A retrospective survey of clinical,pathologic and prognostic features of adnexal masses operated on during pregnancy.J Obstet Gynaecol Res 2000;26:89-93.

20. Balllard CA. Ovarian tumours associated with pregnancy terminationpatients.Am J Obstet Gynecol 1984; 149: 384- 87.

21. Hoffman MS.Primary ovarian cancer during pregnancy,case report.Clin Consult Obstet Gynecol1995; 7: 237.

22. Hogston P, Lilford RJ.Ultrasound study of ovarian cysts in pregnancy: prevalence and significance.Br J Obstet Gynaecol 1986; 93:62528.

23. Sherard GB III,Hodson CA, Williams HJ, Semer DA, Hadi HA, Tait DL. Adnexal masses and pregnancy:A 12years experience.Am J Obstet Gynecol 2003;189:358- 63. 